Aim of the study: To evaluate the intensity of dejection and self-assessment of quality of life in patients with lung cancer from the start of palliative care until death.

Material and methods: The study included 63 patients with lung cancer from the start of care until death in palliative medicine centers in Bydgoszcz in 2012-2013. The visual-analogue scale constituting part of the ESAS scale was used to assess dejection, while question number 30 of the EORTC QLQ-C30 was used for self-assessment of quality of life.

Results: "Moderate" and "very" intense dejection initially occurred in $19(30 \%)$ and 24 (38\%), and in the $2^{\text {nd }}$ assessment in as many as 23 (36\%) and 30 (48\%) patients. Average quality of life deteriorated in this respect by 0.09 in the two-step scale $(p=0.005)$. Increase in the intensity of "moderate" dejection occurred between the $1^{\text {st }}$ and $3^{\text {rd }}$ assessment. Initially it occurred in $2(9 \%)$ patients and in $14(66 \%)$ during the $3^{\text {rd }}$ assessment. In contrast, the levels of "very" severe dejection did not change significantly between the $1^{\text {st }}$ and the $3^{\text {rd }}$ assessment. The average quality of life deteriorated by 0.23 points ( $p=$ $=0.004$ ). A significant relationship was found only between analgesic treatment and quality of life $(p<0.0005)$. Other factors such as age, time from diagnosis to start of treatment, place of residence, sex, or financial condition did not affect the quality of life.

Conclusions: Self-assessment of the quality of life worsens with time. The intensity of dejection does not change in the last 3 weeks of life. In multivariate analysis, among the selected variables such as age, sex, place of residence, time from diagnosis to start of palliative care, financial condition, and type of painkillers used, only the latter has an impact on self-assessed quality of life.

Key words: lung cancer, quality of life, palliative care.

Contemp Oncol (Pozn) 2015; 19 (6): 491-495 DOI: $10.5114 /$ wo. 2015.53250

\section{Dejection and self-assessment of quality of life in patients with lung cancer subjected to palliative care}

\author{
Andrzej Nowicki ${ }^{1}$, Paulina Farbicka ${ }^{1}$, Małgorzata Krajnik²
}

${ }^{1}$ Department of Oncology Nursing, Collegium Medicum in Bydgoszcz, Nicolaus Copernicus University in Torun, Poland

2Department and Unit of Palliative Care, Collegium Medicum, Nicolaus Copernicus University in Torun, Poland

\section{Introduction}

Lung cancer accounts for $12 \%$ of all cancer cases, and has the highest annual rate of mortality in men and women. It is diagnosed at an advanced stage in about $50 \%$ of cases. The general aim is to cure or prolong life without symptoms of the disease [1]. Many patients die with pain and other distressing symptoms such as symptoms of depression, for example, that are not properly controlled. The fear response to cancer significantly reduces the quality of life in persons under 65 years of age in an advanced stage of the disease, while in older people the main problems are related to physical functioning [2]. Evaluation of the quality of life provides information on the symptoms of the disease, adverse effects of therapy but also on assessment of the psychological, social and spiritual dimensions. Systematically performed assessment of quality of life (QoL) in patients with advanced lung cancer can contribute to more accurate clinical assessment of patients and, consequently, more effective symptomatic treatment.

To evaluate intensity of dejection and self-assessment of quality of life in patients with lung cancer from the start of palliative care until death.

\section{Material and methods}

The study was prospective and included patients with lung cancer from the start of palliative care until death in palliative medicine centers in Bydgoszcz in 2012-2013. Initially 228 patients meeting the inclusion criteria were enrolled in the study, of whom 63 persons finally remained in the study (21 women and 42 men). The remaining 76 persons did not complete questionnaires because of difficult or no contact with them, 4 questionnaires were filled only once and 85 people refused to participate. Age of patients was 33-91 years (median 66). Patients were initially treated at home (by a home care team), outpatient palliative clinic or hospice. Overall 147 questionnaires were completed.

The study included patients with lung cancer starting palliative treatment during a period no later than 7 days with similar socioeconomic conditions, in full contact and preserved cognitive function. Patients with other tumors occurring simultaneously with the presence of CNS metastases, treated with pharmacological antidepressants and those who did not consent to the study were excluded.

The visual-analogue scale constituting part of the ESAS scale (a scale of the intensity of symptoms) was used to assess dejection, while question number 30 of the EORTC QLQ-C30 (version 3) was used for self-assessment of the quality of life. The intensity of perceptible dejection was estimated by patients on a scale from 0 (no dejection) to 10 (worst possible dejection). It was assumed that the assessment at the level of 1-3 indicates mild, 4-6 moderate, and 7-10 very strong dejection. A linear transformation of ESAS 
ratings on a scale from 0 (best) to 10 (worst) to a standard scale of $0-1$ assessing the level of dejection was done. Comparison between the intensity of dejection and self-assessment of quality of life was made on the basis of questionnaires collected at three intervals - first, second and third assessment at intervals of 3 weeks. Sixty-three people took part in the $1^{\text {st }}$ and $2^{\text {nd }}$ assessment and only 21 people in the $3^{\text {rd }}$ one. In order to determine the factors that may affect self-assessment of the quality of life, obtained results were analyzed depending on the following variables: age, sex, place of residence, time from diagnosis to starting palliative care, financial situation and type of painkillers used. Univariate and multivariate analysis were performed using Statistica software.

Parametric and non-parametric tests of significance were used in order to verify hypotheses. Pearson linear correlation coefficients were also calculated to identify possible relationships between measurable characteristics. A parametric test was used for the two structural indicators and a non-parametric test of independence, chisquare, in order to determine the correlation between the non-measurable and quality indicators. The $\chi^{2}$ test with Yates' correction was used in case of small number of one of the classes. Student's $t$ test was also used for dependent groups and to evaluate the significance of correlation coefficients.

A significance level of $p=0.05$ was adopted for statistical analysis. When $p<0.05$ the difference or relationship was considered as statistically significant, in other cases as not significant (NS).

All patients were informed about the purpose, procedure, conditions and implementation of the survey and about the possibility to opt out of it at any stage. The study obtained permission from the Bioethics Committee operating at the L. Rydygier Medical College in Bydgoszcz.

\section{Results}

\section{Patient characteristics}

The median time from diagnosis until palliative care was 10 months while palliative care alone was 4 weeks.

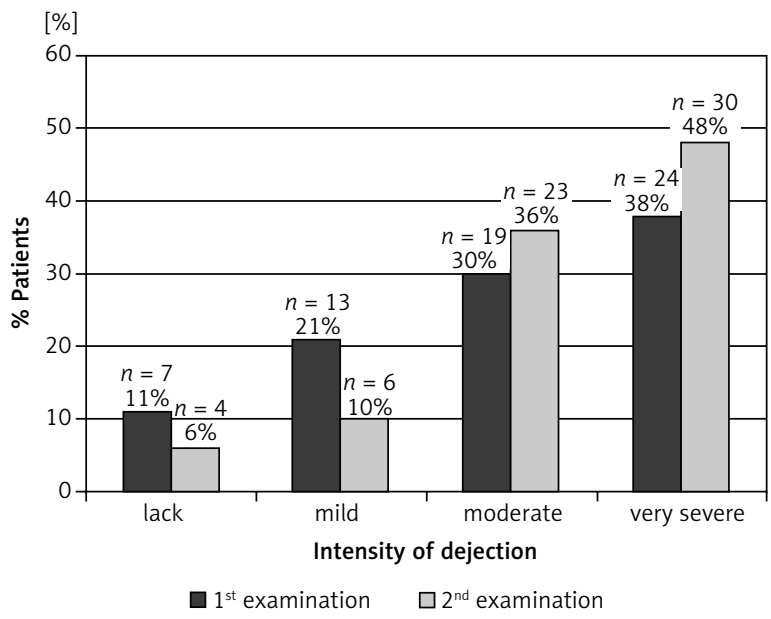

Fig. 1. Intensity of dejection during $1^{\text {st }}$ and $2^{\text {nd }}$ examination $(n=63)$
Intensity of dejection and self-assessment of quality of life

Increase in the intensity of "moderate" and "very" severe dejection was noted between the $1^{\text {st }}$ and $2^{\text {nd }}$ examination. Initially it occurred in 19 (30\%) and 24 (38\%) patients, respectively, and as many as 23 (36\%) and 30 (48\%) patients in the $2^{\text {nd }}$ examination (Fig. 1). In this respect the average quality of life deteriorated by 0.09 in the two-step scale $(p=0.005)$. An increase in the intensity of "moderate" dejection was observed between the $1^{\text {st }}$ and $3^{\text {rd }}$ examination. It occurred initially in $2(9 \%)$ patients and in $14(66 \%)$ during the third examination. The level of "very" severe dejection did not change significantly between the $1^{\text {st }}$ and the $3^{\text {rd }}$ examination (Fig. 2). The average quality of life deteriorated by 0.23 points $(p=0.004)$.

Assessment of the relationship between selected factors: age, sex, place of residence, time from diagnosis to starting palliative care, financial condition, type of painkillers used, and self-assessment of the quality of life. Patients assessed their quality of life for all factors according to the scale from 1 (very poor) to 7 (excellent). None of the patients rated their QoL as "excellent", so the scale has been limited from 1 (very bad self-assessment) to 6 (good).

No correlative dependence was found between age and self-assessed quality of life (Fig. 3). There was also no relationship between self-assessed quality of life and sex, place of residence, time of diagnosis, and the financial condition (Table 2). NSAIDs were taken by 29 (46\%), weak opioids by 13 (20.7\%) and strong opioids by 21 (33.3\%) patients. In the entire group NSAIDs and weak opioids were taken by 42 patients (66.6\%), of whom 23 persons (54.8\%) felt their quality of life as poor (Tables 3, 4). Poor quality of life was reported by 18 (85.7\%) patients taking strong opioids $(p=0.03)$ (Table 4$)$.

The impact of some factors such as age, sex, place of residence, the time of diagnosis, the financial condition and taking painkillers (NSAIDs, weak opioids, strong opioids) on the self-assessment of the quality of life was estimated in multivariate analysis. A significant correlation was found only between analgesic treatment and quality of life $(p<0.0005)$. Other factors such as age, time from

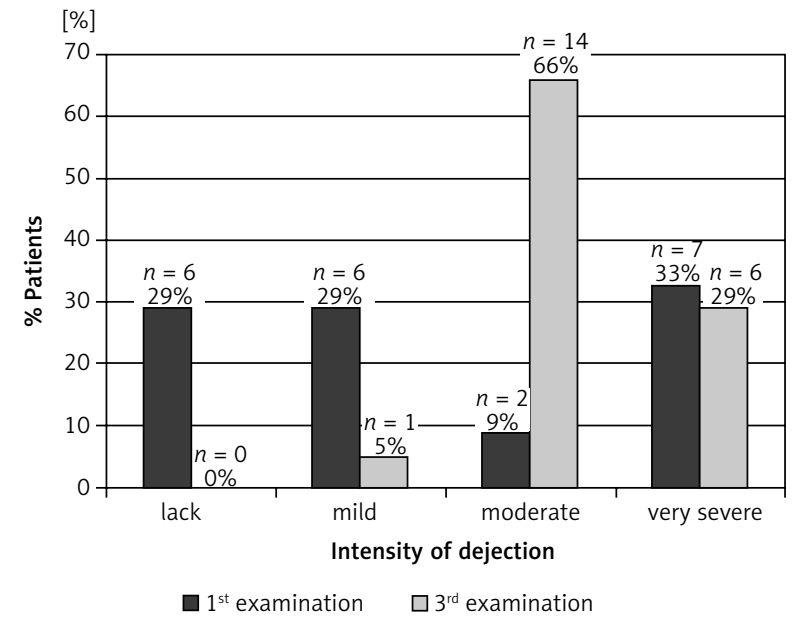

Fig. 2. Intensity of dejection during $1^{\text {st }}$ and $3^{\text {rd }}$ examination $(n=21)$ 
diagnosis to treatment, place of residence, sex, and financial condition did not affect the self-assessment results.

\section{Discussion}

"Very" intense depression occurs in 9-53\% of patients with lung cancer, causing enormous suffering, and can even lead to suicidal thoughts [3]. The symptoms of anxiety and depression are common in patients with lung cancer and may have an impact on quality of life and survival [4-6]. In patients in an advanced stage of cancer, physicians should use proven effective therapies for reducing depression which include tricyclic antidepressants, selective serotonin reuptake inhibitors and psychosocial interventions [7].

Assessment of the intensity of dejection and self-assessment of the quality of life were the basis of the study. There was an increase in "moderate" and "very" severe dejection between the $1^{\text {st }}$ and $2^{\text {nd }}$ assessment procedure. While "moderate" dejection intensified between the 1st and 3rd assessment, the level of "very" severe dejection did not change significantly. This may be related to the fact that in the study where the assessment was made two times dejection was not initially felt by 1 of 10 patients while in three-fold assessment dejection was not initially felt by every 3 patients, and hence there was no "very" intense dejection. In another study including patients with newly diagnosed lung cancer depression was assessed at diagnosis and after 12 weeks. It was observed that in patients enrolled in the early palliative care the level of depression is lower in the second assessment compared to the first one but it is not associated with an improvement in survival rate [8].

Lung cancer often occurs in older people who have co-morbidities. Awareness of the poor prognosis and deteriorating physical functioning are factors that can cause dejection. Although there are effective methods of treatment of these symptoms in patients not suffering from cancer, there is no certainty as to which treatments could be effective for cancer patients. More intensive care is often more appropriate in reducing depressive symptoms than standard care. Treatment of patients with lung cancer with symptoms of depression can be based on the standard treatment although doctors should be aware that the effectiveness and potential side effects of drugs are not known in this group of patients [9]. In a study of patients with advanced lung cancer the occurrence of symptoms of depression and anxiety in the preliminary assessment is reported by every third person. Depression and anxiety affect the quality of life, and they are more common in women and men with low material status [4]. However, in our study "very" severe dejection was initially experienced by more men than women, every five women and one third of men. During the $2^{\text {nd }}$ assessment this type of dejection was felt by almost half of women and more than half of men. The median overall survival time in patients with symptoms of depression is several months and is shorter by $50 \%$ than in patients without this symptom [4]. According to other authors over a dozen percent of patients with lung cancer have diagnosed depression. The diagnosis is

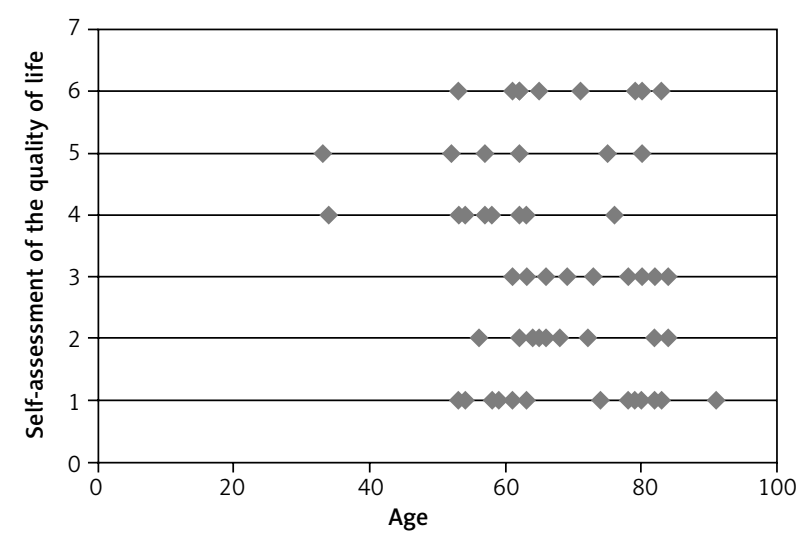

Fig. 3. Age and self-assessment of quality of life (correlation coefficient $-0.196, p=0.12$ )

Table 1. Patient characteristics

\begin{tabular}{|c|c|c|}
\hline Parameter & & $\begin{array}{c}\text { Number of } \\
\text { patients (\%) }\end{array}$ \\
\hline Sex & $\begin{array}{c}\text { male } \\
\text { female }\end{array}$ & $\begin{array}{l}42(67) \\
21(33)\end{array}$ \\
\hline Age & $\begin{array}{l}\text { below } 45 \text { years } \\
46-55 \text { years } \\
56-65 \text { years } \\
66-75 \text { years } \\
76-85 \text { years } \\
\text { above } 86 \text { years }\end{array}$ & $\begin{array}{c}2(3) \\
6(9) \\
22(35) \\
12(19) \\
20(32) \\
1(2)\end{array}$ \\
\hline $\begin{array}{l}\text { Monthly income per } \\
\text { family member }\end{array}$ & $\begin{array}{l}\text { below } 800 \text { PLN } \\
800-1200 \text { PLN } \\
\text { above } 800 \text { PLN }\end{array}$ & $\begin{array}{c}1(2) \\
39(62) \\
23(36)\end{array}$ \\
\hline $\begin{array}{l}\text { Time from diagnosis } \\
\text { to start of palliative } \\
\text { care }\end{array}$ & $\begin{array}{c}\text { one year or less } \\
2 \text { years } \\
3 \text { years } \\
4 \text { years and more }\end{array}$ & $\begin{array}{c}34(54) \\
24(38) \\
3(5) \\
2(3)\end{array}$ \\
\hline $\begin{array}{l}\text { Duration of } \\
\text { palliative care }\end{array}$ & $\begin{array}{l}3 \text { weeks } \\
6 \text { weeks }\end{array}$ & $\begin{array}{l}42(67) \\
21(33)\end{array}$ \\
\hline
\end{tabular}

associated with increased mortality among all patients, except patients in an advanced stage of cancer, where the survival rate is very low [6].

Multivariate analysis was the final phase of our study. The influence of selected variables such as age, sex, place of residence, time from diagnosis until palliative care, financial condition and use of painkillers (NSAIDs, weak opioids, strong opioids) on the self-assessment of the quality of life of patients was estimated. A significant correlation was found only between analgesic treatment and quality of life. Other factors had no effect. In the study group, more than half of patients took NSAIDs and weak opioids, and nearly half of them rated their quality of life as good. However, in the group of patients receiving strong opioids the majority of patients had a poor self-assessment of the quality of life. The poor self-assessment of the quality of life associated with the intake of opioids may be due to side effects of painkillers, mainly constipation. It is estimated that constipation occurs in about half of patients with cancer. This number increased in the incurable pa- 
Table 2. Selected factors and self-assessment of quality of life

\begin{tabular}{|c|c|c|c|c|c|c|c|c|}
\hline \multirow[t]{3}{*}{ Selected factor } & & \multicolumn{6}{|c|}{ Quality of life self-assessment scale } & \multirow[t]{3}{*}{$p$} \\
\hline & & 1 & 2 & 3 & 4 & 5 & 6 & \\
\hline & & \multicolumn{6}{|c|}{ Number of patients } & \\
\hline \multirow[t]{2}{*}{ Sex } & female & 5 & 4 & 4 & 2 & 2 & 4 & \multirow[t]{2}{*}{0.93} \\
\hline & male & 11 & 9 & 8 & 6 & 4 & 4 & \\
\hline \multirow[t]{2}{*}{ Place of residence } & city & 15 & 12 & 10 & 6 & 6 & 8 & \multirow[t]{2}{*}{0.46} \\
\hline & village & 1 & 1 & 2 & 2 & 0 & 0 & \\
\hline \multirow[t]{2}{*}{ Time of diagnosis } & $\leq$ a year ago & 7 & 7 & 7 & 6 & 3 & 4 & \multirow[t]{2}{*}{0.73} \\
\hline & $>1$ year & 9 & 6 & 5 & 2 & 3 & 4 & \\
\hline \multirow[t]{2}{*}{ Financial condition } & $<1200$ PLN & 8 & 10 & 8 & 6 & 2 & 6 & \multirow[t]{2}{*}{0.35} \\
\hline & $\geq 1200$ PLN & 8 & 3 & 4 & 2 & 4 & 2 & \\
\hline
\end{tabular}

Table 3. Analgesic medications and self-assessment of quality of life $(n=63)$

\begin{tabular}{|c|c|c|c|c|c|c|c|c|}
\hline \multirow[t]{3}{*}{ Analgesic medications } & \multicolumn{6}{|c|}{ Quality of life self-assessment scale } & \multirow[t]{3}{*}{ Total } & \multirow[t]{3}{*}{$p$} \\
\hline & 1 & 2 & 3 & 4 & 5 & 6 & & \\
\hline & \multicolumn{6}{|c|}{ Number of patients } & & \\
\hline NSAID & 3 & 4 & 6 & 6 & 3 & 7 & 29 & \multirow[t]{4}{*}{0.03} \\
\hline Weak opioids & 3 & 5 & 2 & 0 & 2 & 1 & 13 & \\
\hline Strong opioids & 10 & 4 & 4 & 2 & 1 & 0 & 21 & \\
\hline Total & 16 & 13 & 12 & 8 & 6 & 8 & 63 & \\
\hline
\end{tabular}

Table 4. Analgesic medications and bad or better quality of life $(n=63)$

\begin{tabular}{lccc} 
& \multicolumn{2}{c}{ Quality of life } & \multicolumn{1}{c}{ Total } \\
\cline { 2 - 4 } & $\mathbf{1 , 2 , 3 ( \mathrm { bad } )}$ & $\mathbf{4 , 5 , 6 ( \mathrm { good } )}$ \\
NSAID and weak opioids & $23(54.8 \%)$ & $19(45.2 \%)$ & $\mathbf{4}$ \\
Strong opioids & $18(85.7 \%)$ & $3(14.3 \%)$ & 21 \\
Total & 41 & 22 & 63
\end{tabular}

tients and those taking opioids. Constipation may be the most common side effect associated with the intake of these drugs $[10,11]$. Assessing pain in palliative care in patients with lung cancer, it is observed that the most frequently administered drugs in this group of patients are strong opioids, and constipation is observed in half of them [12]. It is difficult to rule out the influence of the other symptoms of advanced cancer on the deteriorating self-assessed quality of life.

Palliative care is an important component of cancer treatment. Its introduction improves the quality of life, relieves coexisting symptoms, and reduces the use of futile intensive care. Surveys of the quality of life and self-assessment of this quality provide valuable information from patients about the symptoms of the disease but also evaluate the emotional, public and social dimensions. Results can bring new insights into palliative care of patients with lung cancer in order to reduce the problems and side effects, which can improve their quality of life. Research conducted on a larger number of patients, which can be difficult to do in practice, will allow us to determine the mental state, especially in terms of dejection and self-as- sessment of the quality of life, more accurately in the last period of an incurable disease that gets worse for obvious reasons. Our research shows that factors not directly related to advanced lung cancer have no effect on quality of life. In addition, probably a short period of palliative care of these patients can affect the dynamically deteriorating mental and physical condition.

In conclusions:

1. Self-assessment of the quality of life worsens with time.

2. The intensity of dejection did not change in the last 3 weeks of life.

3. In multivariate analysis among the selected variables such as age, sex, place of residence, time from diagnosis to starting palliative care, financial condition, and type of painkillers used, only the latter has an impact on self-assessed quality of life.

4. Duration of palliative care in patients with advanced lung cancer is short: 4 weeks.

The authors declare no conflict of interest. 


\section{References}

1. Ramalingam SS, Owonikoko TK, Khuri FR. Lung Cancer: New biological insights and recent therapeutic advances. Cancer J Clin 2011; 61: 91-112.

2. Modlińska A, Buss T, Krakowiak P. Ocena jakości życia osób w wieku podesztym w terminalnym okresie choroby nowotworowej. Przeg Lek 2009; 66: 479-84.

3. Shimizu K, Nakaya N, Saito-Nakaya K, et al. Clinical biopsychosocial risk factors for depression in lung cancer patients: a comprehensive analysis using data from the Lung Cancer Database Project. Ann Oncol 2012; 23: 1973-9.

4. Arrieta O, Angulo LP, Núñez-Valencia C, Dorantes-Gallareta Y, Macedo EO, Martinez-Lopez, Alvarado S, Corona-Cruz JF, Oñate-Ocaña LF. Association of depression and anxiety on quality of life, treatment adherence, and prognosis in patients with advanced nonsmall cell lung cancer. Ann Surg Oncol 2013; 20: 1941-8.

5. Brown Johnson CG, Brodsky JL, Cataldo JK. Lung cancer stigma, anxiety, depression, and quality of life. J Psychosoc Oncol 2014; 32: 59-73.

6. Sullivan DR, Ganzini L, Duckart JP, Lopez-Chavez A, Deffebach ME, Thielke SM, Slatore CG. Treatment receipt and outcomes among lung cancer patients with depression. Clin Oncol 2014; 2: 25-31.

7. Qaseem A, Snow V, Shekelle P, Casey DE Jr, Cross JT Jr, Owens DK; Clinical Efficacy Assessment Subcommittee of the American College of Physicians. Evidence-based interventions to improve the palliative care of pain, dyspnea, and depression at the end of life: a clinical practice guideline from the American College of Physicians. Ann Intern Med 2008; 15: 141-6.

8. Pirl WF, Greer JA, Traeger L, Jackson V, Lennes IT, Gallagher E, Sequist L, Temel JS. Depression and survival in metastatic non-smallcell lung cancer: effects of early palliative care. J Clin Oncol 2012; 30: 1310-5.

9. Walker J, Sawhney A, Hansen CH, Symeonides S, Martin P, Murray G Sharpe M. Treatment of depression in people with lung cancer: a systematic review. Lung Cancer 2013; 79: 46-53.

10. Ahmedzai SH, Boland J. Constipation in people prescribed opioids. Clin Evid 2010; 6: 61-6.

11. Clark K, Byfieldt N, Dawe M, Currow DC. Treating constipation in palliative care: the impact of other factors aside from opioids. Am J Hosp Palliat Care 2012; 29: 122-5.

12. Nowicki A, Staszewska A. Ocena bólu nowotworowego w opiece paliatywnej u chorych na raka płuca. Polska Medycyna Paliatywna 2006; 5: 154-61.

\section{Address for correspondence}

Andrzej Nowicki Associate Prof. Collegium Medicum in Bydgoszcz Nicolaus Copernicus University Techników 3

85-801 Bydgoszcz

e-mail: anow1_xl@wp.pl

Submitted: 20.04 .2015

Accepted: 28.07.2015 